\title{
Usefulness of urinary collagen IV excretion for predicting the severity of Henoch-Schönlein nephropathy children
}

\author{
MAEGORZATA MIZERSKA-WASIAK ${ }^{1}$, KAROLINA CICHON'-KAWA', JADWIGA MAEDYK', \\ ELŻBIETA GÓRSKA ${ }^{3}$, URSZULA DEMKOW', MAŁGORZATA PAŃCZYK-TOMASZEWSKA ${ }^{l}$ \\ ${ }^{1}$ Department of Pediatric and Nephrology, Medical University of Warsaw, Poland \\ ${ }^{2}$ Department of Pathology, Medical University of Warsaw, Poland \\ ${ }^{3}$ Department of Laboratory Diagnostics and Clinical Immunology of Developmental Age, Medical University of Warsaw, Poland
}

\begin{abstract}
The aim of the study was to evaluate the usefulness of urinary collagen IV (Col IV) excretion for predicting the severity of autoimmune renal inflammation in children with HSN (Henoch-Schönlein nephritis).

Material and methods: We studied 26 children, in whom HSN was diagnosed based on kidney biopsy. In all patients, urinalysis was performed and 24-hour urinary protein excretion was measured at the onset of the disease. All kidney biopsies were also scored using the Oxford classification: $M-$ mesangial hypercellularity score (M0 absent, M1 present); $E$ - presence of endocapillary proliferation (EO absent, E1 present), $S$ - segmental glomerulosclerosis/adhesion (SO absent, S1 present), $T$-tubular atrophy/interstitial fibrosis (TO $\leq 25 \%, T 126-50 \%, T 2>50 \%)$. The MEST score was calculated as the sum of $M+E+S+T$.

Results: Urinary Col IV level was significantly higher in the study group than in control group. Urinary Col IV level was insignificantly higher in group A (nephrotic proteinuria) compared to the $B$ (non-nephrotic proteinuria) and $C$ (without proteinuria).We found no significant differences in the age at the disease onset, severity of proteinuria, and Col IV between groups $1(S O, T O)$ and 2.(S1,T1/T2). The MEST score was significantly higher in group 2 than group 1.

Conclusions: Urinary Col IV excretion in children with HSN may be related to the lesions severity by the Oxford classification but seems to be associated with the mean value (the MEST score).

In younger children, a more aggressive disease course is observed, and thus earlier and more aggressive treatment should be considered in this group.
\end{abstract}

Key words: Henoch-Schönlein nephritis, Oxford classification, collagen type IV, children.

(Cent Eur J Immunol 2017; 42 (2):167-172)

\section{Introduction}

Henoch-Schönlein purpura (HSP, or IgA vasculitis according to the new classification) is a result of autoimmune inflammatory process involving small vessels, mostly within the skin, joints, gastrointestinal tract, and kidneys [1-5].

HSP is considered a type of leukocytoclastic vasculitis [2]. Histopathologically, it is characterized by endothelial cell edema, fibrinoid necrosis within the vessel wall, and intramural cellular infiltrates consisting primarily of neutrophils and fragments of their nuclei.

The disease may begin at any age, but mostly in children aged 3-8 years, predominantly boys (with the male:female ratio of $1.5: 1$ to $4: 1$ ) [3].
Similarly to IgA nephropathy (IgAN), the major process underlying the pathogenesis of Henoch-Schönlein nephropathy (HSN) is abnormal glycosylation of $\operatorname{IgA} 1$ in the hinge region, leading to formation of aberrantly glycosylated IgA1 terminated with $\mathrm{N}$-acetylgalactosamine (GalNAc) or sialylated GalNAc. The latter stimulates antibody production, leading to formation of nephritogenic immune complexes and their mesangial deposition [4-6].

Genetic factors that modulate the immune response may also contribute to individual predisposition to HSP [5].

Symptoms of HSN include proteinuria/nephrotic syndrome, nephritic syndrome, isolated microscopic/macroscopic hematuria, and even acute kidney injury [2-4].

Correspondence: Małgorzata Mizerska-Wasiak, Department of Pediatric and Nephrology, Medical University of Warsaw,

Zwirki i Wigury 63A, 02-091 Warsaw, Poland, e-mail: wasiaczki@wp.pl

Submitted: 1.06.2017; Accepted: 10.06.2017 
The Oxford classification developed in 2009 describes prognostically adverse kidney biopsy findings including mesangial proliferation, endocapillary hypercellularity, sclerosis, and tubular atrophy/interstitial fibrosis $[8,9]$. This classification is used in IgAN but it has also been studied in HSN [9]. Several studies evaluated the prediction effect of the MEST classification, and the MEST score combined with clinical symptoms may help evaluate prognosis and guide therapeutic decisions [10].

Renal tubulointerstitial fibrosis depends on the accumulation of extracellular matrix proteins including collagen IV (Col IV) and fibronectin [11]. One hypothesis postulates that this is related to interstitial fibroblast activation, migration of mesenchymal stem cells from the bone marrow, or transformation of renal tubular epithelial cells into cells that produce extracellular matrix proteins. Other authors believe that the key role tubulointerstitial fibrosis is played by myofibroblasts originating from interstitial fibroblasts, proliferation of which and their association with TGF- $\beta$ and Col IV production has been observed in both experimental models and clinical studies on nephropathy [11-14]. Collagen IV is deposited between damaged renal tubular cells and transformed interstitial cells. Interstitial myofibroblasts and damaged renal tubular epithelial cells are responsible for interstitial fibrosis [14-16].

Renal tubular cells may be the source of factors initiating fibrogenesis, and tubular atrophy may potentially lead to an increased number or interstitial fibroblasts [17-19].

Search for markers of chronic glomerulonephritis based on the evaluation of the severity of the fibrosis process by measuring levels of, among others, fibronectin, Col IV and laminin in various body fluids or evaluating their presence in glomeruli continues to be an area of active research $[10,15]$

The aim of the study was to evaluate the usefulness of urinary Col IV excretion for predicting the severity of autoimmune renal inflammation in children with HSN.

\section{Material and methods}

We studied 26 children (including 15 boys and 11 girls, mean age $10.65 \pm 3.68$ years) hospitalized in the Department of Pediatrics and Nephrology in whom HSN was diagnosed based on kidney biopsy.

In all patients, urinalysis was performed and 24-hour urinary protein excretion was measured at the onset of the disease. In addition, Col IV excretion was measured in 24hour urinary collection. Based on 24-hour urinary excretion, nephrotic range ( $\geq 50 \mathrm{mg} / \mathrm{kg} /$ day) or non-nephrotic range $(<50 \mathrm{mg} / \mathrm{kg} /$ day $)$ proteinuria was diagnosed.

Serum measurements included renal function parameters including urea and creatinine (in $\mathrm{mg} / \mathrm{dl}$ ), and the glomerular filtration rate (GFR) was calculated using the Schwartz formula (in $\mathrm{ml} / \mathrm{min} / 1.73 . \mathrm{m}^{2}$ ) [19].

To evaluate immunological parameters of the disease process, serum measurements included immune globulins IgA, IgG, and IgM, and complement components C3 and C4. Serum urea and creatinine were measured by dry chemistry methods using the Vitros 250 system.

Immune globulins $\operatorname{IgA}, \operatorname{IgG}$, and $\operatorname{IgM}$ were measured by the nephelometric method using the Array 360 system. Age-specific reference ranges are shown in the Table 1.

Complement components $\mathrm{C} 3$ and $\mathrm{C} 4$ were measured by the nephelometric method using the Array 360 system. Reference ranges were $88-207 \mathrm{mg} / \mathrm{dl}$ for C3 and 16-47 mg/ $\mathrm{dl}$ for $\mathrm{C} 4$. Urinary protein level in urinalysis samples was measured by the turbidimetric Exton method (reference range up to $10 \mathrm{mg} / \mathrm{dl}$ ).

The number of erythrocytes in urine sediment was evaluated by light microscopy at 40-fold magnification (reference range up to 5 erythrocytes per field of view). Twenty-four hour urinary protein excretion (in $\mathrm{mg} / \mathrm{kg} /$ day) was measured by the turbidimetric Exton method. Proteinuria up to $150 \mathrm{mg}$ /day is considered a normal finding.

Collagen IV was measured in 24-hour urinary collection by the immunoenzymatic competitive method. Polystyrene plates (Falcon, Germany) were coated with colla-

Table 1. Normal serum immune globulin levels in children in relation to age

\begin{tabular}{|c|c|c|c|}
\hline Age & IgG (mg/dl) & IgA (mg/dl) & $\operatorname{IgM}(\mathrm{mg} / \mathrm{dl})$ \\
\hline 4-6 months & $256-609$ & 4-36 & $48-189$ \\
\hline 7-12 months & $299-771$ & $9,8-70$ & $56-144$ \\
\hline 1.1-3 years & $462-1347$ & $15-154$ & $42-278$ \\
\hline $3.1-5$ years & $530-1127$ & $12-202$ & $65-178$ \\
\hline $5.1-8$ years & $526-1527$ & $47-203$ & $63-204$ \\
\hline 8.1-12 years & $618-1537$ & $57-233$ & $57-241$ \\
\hline 12.1-14 years & $682-1500$ & $60-304$ & $52-321$ \\
\hline 14.1-16 years & $570-1660$ & $56-272$ & $56-364$ \\
\hline$>16$ years & $663-1587$ & $66-370$ & $52-351$ \\
\hline
\end{tabular}


gen IV preparation obtained from human placenta (Sigma, USA). Urine samples concentrated 4-fold were added to the prepared plate, followed by addition of a conjugate - a solution of rabbit antibodies against murine IgG conjugated with horseradish peroxidase (DAKO, Denmark). The next step involved addition of a horseradish peroxidase substrate, orthophenyldiamine (Sigma, USA). The reaction was then blocked with $6 \mathrm{~N}$ sulphuric acid, and the intensity of absorbance was read at $492 \mathrm{~nm}$ using the Leader 210 reader. The standard curve was prepared based on absorbance measurements in human Col IV solutions at various concentrations subjected to the above reactions. Urinary col IV content was expressed in $\mathrm{ng} / \mathrm{mg}$ creatinine.

Measurements were made in the laboratory of the Department of Immunology, Transplantology, and Internal Medicine of Warsaw Medical University. The values obtained were compared with a control group. The control group included 18 healthy children matched for gender and age, in whom 24-hour urinary Col IV excretion was measured along with urinalysis and serum urea and creatinine measurements.

Renal tissue specimens were obtained by needle biopsy, using automated Magnum biopsy needle, or surgically. The choice of the tissue sampling method depended on the patient's age and clinical condition. Biopsy kidney specimens were evaluated by light microscopy and immunofluorescence.

Following tissue sampling, 1/3 of the sample was fixed in $10 \%$ formaldehyde stabilized with phosphate buffer at pH 7.2, transferred to paraffin, and cut into 3-5 $\mu \mathrm{m}$ slices. Paraffin-embedded slices were stained with hematoxylin-eosin (HE), azan, periodic acid-Schiff, and impregnated with silver salts by the Johnson method.

Immunofluorescence testing was performed by indirect immunofluorescence using immunofluorescence monoclonal sera $(\mathrm{DAKO})$ that contained antibodies against $\operatorname{IgA}$, $\mathrm{IgG}, \mathrm{IgM}, \mathrm{C} 1$, and $\mathrm{C} 3$. These sera produced a color reaction that allowed identification of specific deposits and their location in the kidney tissue.

All kidney biopsies were also scored using the Oxford classification: $\mathrm{M}$ - mesangial hypercellularity score (M0 absent, $\mathrm{M} 1$ present); $\mathrm{E}$ - presence of endocapillary proliferation (E0 absent, E1 present), S - segmental glomerulosclerosis/ adhesion (S0 absent, $\mathrm{S} 1$ present), $\mathrm{T}$ - tubular atrophy/interstitial fibrosis ( $\mathrm{T} 0 \leq 25 \%, \mathrm{~T} 126-50 \%$, T2 $>50 \%$ ). The MEST score was calculated as the sum of $\mathrm{M}+\mathrm{E}+\mathrm{S}+\mathrm{T}[7,8]$.

\section{Statistical analysis}

Results were expressed as mean values with standard deviation, or medians and ranges for non-normally distributed variables. Two group comparisons were performed using the Student $t$ test, and the Mann-Whitney $U$ test in case of non-normally distributed variables (proteinuria and age at the onset of the disease).
Comparisons of several groups were performed using ANOVA and the Kruskal-Wallis test.

Correlations were calculated using the linear regression method.

\section{Results}

Study group characteristics are shown in Table 2.

Boys comprised $58 \%$ of the study group. Symptoms of nephropathy were observed (on average?) after 2 weeks of the disease but they might also be present at the disease onset or develop after up to 1.8 years.

Among symptoms of nephropathy, erythrocyturia was found in all children, accompanied by nephrotic range proteinuria in $42 \%$ of children, and non-nephrotic range proteinuria in $31 \%$ of children. All patients had normal GFR at the disease onset.

In the study group, elevated IgA level was found in 12 $(46 \%)$ of children, IgM in one child (4\%), and reduced IgG level in $6(23 \%)$ of patients.

$\mathrm{C} 3$ level was reduced in $6(23 \%)$ children, and C4 level was reduced in $2(8 \%)$ children. Reduction of both $\mathrm{C} 3$ and $\mathrm{C} 4$ level was not seen in any the children.

The mean severity of IgA deposits in kidney biopsy was +3 .

Table 2. Study group characteristics

\begin{tabular}{|c|c|}
\hline Parameter & HSN $(n=26)$ \\
\hline Age [years] & $10.43 \pm 3.55$ \\
\hline Gender (M/F) & $15 / 11$ \\
\hline Time to nephropathy [weeks] & $2(0-96)$ \\
\hline Proteinuria [mg/kg/day] & $32(0-600)$ \\
\hline GFR $\left[\mathrm{ml} / \mathrm{min} / 1.73 \mathrm{~m}^{2}\right]$ & $152.9 \pm 36.6$ \\
\hline $\operatorname{IgA}[\mathrm{mg} / \mathrm{dl}]$ & $275.81 \pm 111.65$ \\
\hline $\operatorname{IgG}[\mathrm{mg} / \mathrm{dl}]$ & $927.23 \pm 373.83$ \\
\hline $\operatorname{IgM}[\mathrm{mg} / \mathrm{dl}]$ & $134.5 \pm 47.36$ \\
\hline $\mathrm{C} 3[\mathrm{mg} / \mathrm{dl}]$ & $108.1 \pm 28.96$ \\
\hline $\mathrm{C} 4[\mathrm{mg} / \mathrm{dl}]$ & $24.68 \pm 11.59$ \\
\hline Kidney biopsy & $n=28$ \\
\hline IgA in kidney biopsy specimen* & $3.0 \pm 0.88$ \\
\hline M1 (n) & 26 \\
\hline E1 (n) & 4 \\
\hline $\mathrm{S} 1(\mathrm{n})$ & 5 \\
\hline $\mathrm{T} 1 / \mathrm{T} 2$ (n) & 9 \\
\hline MEST score & $1.69 \pm 0.73$ \\
\hline Col IV (ng/mg creat) & $44.27 \pm 42.10^{* * *}$ \\
\hline Col IV (ng/mg creat) - control group & \\
\hline
\end{tabular}


By the Oxford classification, mesangial hypercellularity (M1) was seen in all patients (100\%), E1 in $15 \%$, and $\mathrm{S} 1$ or $\mathrm{T} 1 / 2$ in $54 \%$ of children. The mean MEST score was $1.69 \pm 0.73$.

Urinary Col IV level was significantly higher in the study group compared to the control group.

The evaluated parameters were compared between groups stratified by the severity of proteinuria (group $\mathrm{A}$ - nephrotic range proteinuria, group B - non-nephrotic range proteinuria, group $\mathrm{C}$ - no proteinuria), as shown in Table 3.

Age at the disease onset was significantly lower in group A compared to groups B and C $(p<0.05)$. Group A showed significantly more common endocapillary pro- liferation compared to groups B and C. No significant differences were found in the rates of mesangial hypercellularity, segmental glomerulosclerosis/adhesion, and tubular atrophy/interstitial fibrosis.

Urinary Col IV level was insignificantly higher in group A compared to the other groups.

The study group was also evaluated for the presence of $\mathrm{S} 1$ or T1/T2 lesions Gr 1), as shown in Table 4.

We found no significant differences in the age at the disease onset, severity of proteinuria, and levels of immune globulins, complement components, and Col IV between groups 1 (S1, T1/T2) and 2 (S0, T0).

The MEST score was significantly higher in group 2 compared to group $1(p<0.0001)$.

Table 3. Col IV level and histopathologic changes in relation to the severity of proteinuria

\begin{tabular}{lcccc}
\hline & $\begin{array}{c}\text { Group A } \\
\text { Nephrotic range } \\
\text { proteinuria } \\
(\boldsymbol{n}=\mathbf{1 1})\end{array}$ & $\begin{array}{c}\text { Group B } \\
\text { Non-nephrotic range } \\
\text { proteinuria } \\
(\boldsymbol{n}=\mathbf{9})\end{array}$ & $\begin{array}{c}\text { Group C } \\
\text { No proteinuria } \\
(\boldsymbol{n}=\mathbf{6})\end{array}$ & $\boldsymbol{P}$ \\
\hline Age at disease onset [years] & $8.93 \pm 3.7$ & $10.68 \pm 3.37$ & $12.82 \pm 2.35$ & $<0.05$ \\
\hline Time to nephropathy [weeks] & $0(0-4)$ & $3(0-96)$ & $5.5(2-78)$ & NS \\
\hline IgA [mg/dl] & $237.28 \pm 119.87$ & $295.56 \pm 105.88$ & $316.83 \pm 98.33$ & NS \\
\hline IgG [mg/dl] & $687.09 \pm 395.51$ & $1012.89 \pm 233.59$ & $1239.0 \pm 204.64$ & $<0.01$ \\
\hline IgM $[\mathrm{mg} / \mathrm{dl}]$ & $131.33 \pm 49.78$ & $137.64 \pm 57.21$ & $135.62 \pm 31.37$ & NS \\
\hline $\mathrm{C} 3[\mathrm{mg} / \mathrm{dl}]$ & $98.2 \pm 32.76$ & $116.48 \pm 28.99$ & $113.68 \pm 18.01$ & NS \\
\hline $\mathrm{C} 4[\mathrm{mg} / \mathrm{dl}]$ & $22.93 \pm 6.9$ & $28.39 \pm 18$ & $22.33 \pm 4.47$ & $\mathrm{NS}$ \\
\hline $\mathrm{M} 1$ & 11 & 9 & 6 & $\mathrm{NS}$ \\
\hline $\mathrm{E} 1$ & 4 & 0 & 0 & $<0.05$ \\
\hline $\mathrm{S} 1$ & 2 & 2 & 1 & $\mathrm{NS}$ \\
\hline $\mathrm{T} 1$ & 5 & 2 & $1.50 \pm 0.84$ & $\mathrm{NS}$ \\
\hline $\mathrm{Col} \mathrm{IV}$ & $2.00 \pm 0.45$ & $1.44 \pm 0.88$ & $\mathrm{NS}$ \\
\hline
\end{tabular}

Table 4. Col IV level in relation to $\mathrm{S}$ and $\mathrm{T}$ score

\begin{tabular}{|c|c|c|c|}
\hline & $\begin{array}{c}\text { Group 1 } \\
\mathrm{S}=\underset{0 \text { and } \mathrm{T}=0}{(n=16)}\end{array}$ & $\begin{array}{c}\text { Group } 2 \\
\mathrm{~S}=1 \text { or } \mathrm{T} \geq \mathbf{1} \\
(\boldsymbol{n}=\mathbf{1 0})\end{array}$ & $p$ \\
\hline Age at disease onset [years] & $9.89 \pm 3.94$ & $11.31 \pm 2.79$ & NS \\
\hline Age at the time of nephropathy [years] & $10.06 \pm 4.14$ & $11.6 \pm 2.7$ & NS \\
\hline Proteinuria [mg/kg/day] & $0(0-600)$ & $23.1(0-121)$ & NS \\
\hline $\operatorname{IgA}[\mathrm{mg} / \mathrm{dl}]$ & $267.38 \pm 96.48$ & $289.31 \pm 137.06$ & NS \\
\hline $\operatorname{IgG}[\mathrm{mg} / \mathrm{dl}]$ & $920.25 \pm 395.75$ & $938.4 \pm 356.28$ & NS \\
\hline $\operatorname{IgM}[\mathrm{mg} / \mathrm{dl}]$ & $124.01 \pm 45.02$ & $151.3 \pm 47.15$ & NS \\
\hline $\mathrm{C} 3[\mathrm{mg} / \mathrm{dl}]$ & $106.28 \pm 31.21$ & $111.02 \pm 26.3$ & NS \\
\hline $\mathrm{C} 4[\mathrm{mg} / \mathrm{dl}]$ & $24.78 \pm 13.79$ & $24.52 \pm 7.5$ & NS \\
\hline GFR & $149.21 \pm 28.88$ & $152.59 \pm 29.1$ & NS \\
\hline MESTsc & $1.25 \pm 0.45$ & $2.40 \pm 0.52$ & $<0.0001$ \\
\hline Col IV (ng/mg creat) & $50.15 \pm 48.83$ & $39.30 \pm 29.00$ & NS \\
\hline
\end{tabular}


Table 5. Relations between evaluated parameters and MEST score in children with HSN

\begin{tabular}{lccc} 
& Group MEST $\mathbf{1}$ & Group MEST $>\mathbf{1}$ & $\boldsymbol{p}$ \\
\hline Age at disease onset [years] & $10.79 \pm 3.75$ & $10.08 \pm 3.45$ & NS \\
\hline Age at the time of nephropathy [years] & $11.01 \pm 3.96$ & $10.29 \pm 3.49$ & NS \\
\hline Proteinuria [mg/kg/day] & $0(0-31.3)$ & $29.1(0-600)$ & NS \\
\hline IgA [mg/dl] & $288.31 \pm 95.87$ & $263.32 \pm 128.22$ & NS \\
\hline IgG [mg/dl] & $1051.38 \pm 282.43$ & $803.08 \pm 421.88$ & NS \\
\hline IgM [mg/dl] & $136.73 \pm 50.93$ & $132.28 \pm 45.49$ & NS \\
\hline $\mathrm{C} 3[\mathrm{mg} / \mathrm{dl}]$ & $116.57 \pm 26.8$ & $99.63 \pm 29.57$ & $\mathrm{NS}$ \\
\hline $\mathrm{C} 4[\mathrm{mg} / \mathrm{dl}]$ & $25.88 \pm 15.13$ & $23.38 \pm 6.92$ & $\mathrm{NS}$ \\
\hline $\mathrm{Col} \mathrm{IV}$ & $1.08 \pm 0.28$ & $2.31 \pm 0.48$ & $\mathrm{NS}$ \\
\hline
\end{tabular}

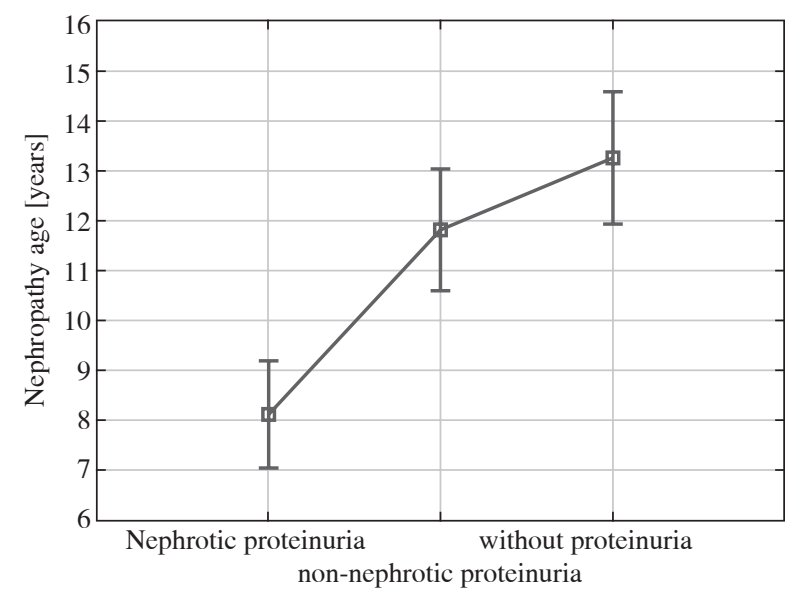

Fig. 1. Relation between the severity of proteinuria at the onset of the disease and the age at the onset of the disease in children with HSN

We also compared groups stratified by the MEST score, as shown in Table 5.

Groups with the MEST score of 1 vs. > 1 did not differ in any of the evaluated parameters.

Nephrotic range proteinuria was found significantly more frequently in younger children (group A), as shown in Fig. 1.

In the study group, we found a negative correlation between the age at the time of nephropathy and urinary Col IV level, as shown in Fig. 2.

\section{Discussion}

Urinary Col IV excretion in children with HSN was significantly higher compared to the control group ( $p<$ 0.05 ), which is consistent with the results obtained by other authors who found higher collagen levels in children with glomerulonephritis compared to the control group $[20,21]$. This may confirm the presence of tubulointersti-

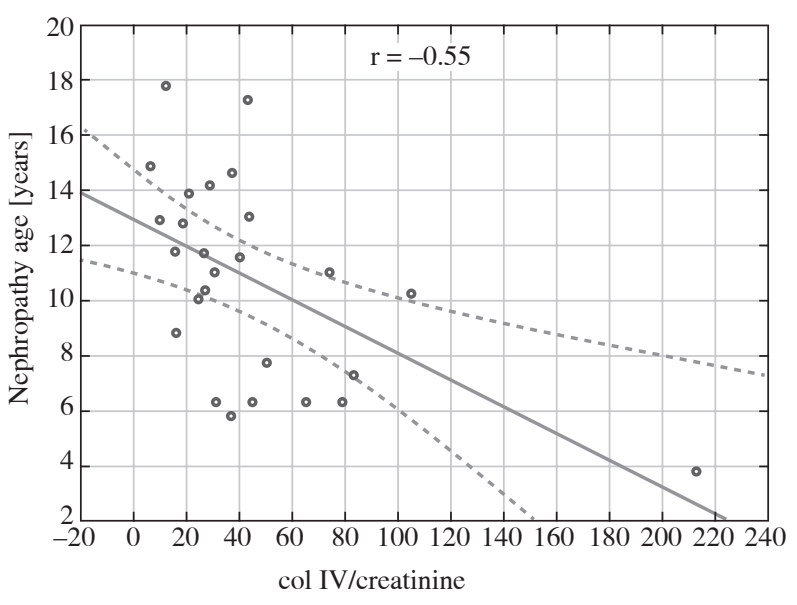

Fig. 2. Relation between collagen IV excretion and the age at the onset of the disease in children with HSN

tial changes and is consistent with the studies by other authors who found Col IV accumulation within the damaged interstitium and renal tubules [12-14].

In the study group, we found a negative correlation $(r=-0.55, p<0.01)$ between urinary Col IV level and the age at the onset of HSN which, in association with a significantly lower age of children with nephrotic range proteinuria, may suggest a more severe disease course in younger children.

In our previous studies, we found dynamic changes of urinary Col IV level in patients with IgAN, which may indicate a treatment effect on urinary Col IV excretion [20].

Use of the Oxford classification to evaluated prognostically adverse factors in HSN is in agreement with the studies by Nasri et al. and Kim et al. who showed that the Oxford classification is useful for the evaluation of prognosis in this patient group, similarly to $\operatorname{IgAN}[9,22]$. The presence of segmental glomerulosclerosis/adhesion (S1) and interstitial fibrosis with tubular atrophy (T1/T2) com- 
bined with nephrotic range proteinuria were found to be particularly useful as early predictors of adverse outcomes [10]. In our study group, we did not find significant differences in urinary Col IV excretion in children with nephrotic range proteinuria, and these patients were not found to present significantly more frequently with $\mathrm{S} 1$ or T1/T2. In children with S1 and/or T1, we found a significantly higher MEST score, indicating that the MEST score may be more useful in children with HSN compared to $\operatorname{IgAN}$, as also shown by other authors [10].

\section{Conclusions}

Urinary Col IV excretion in children with HSN may be related to the lesion severity by the Oxford classification but seems to have no association with specific MEST prognostic factors, and is only associated with the mean value (the MEST score).

In younger children, a more aggressive disease course is observed, and thus earlier and more aggressive treatment should be considered in this group.

\section{The authors declare no conflict of interest.}

\section{References}

1. Berger J, Hinglais N (1968): Les depots intercapillaires d'IgA-IgG. J Urol Nephrol (Paris) 74: 694-695.

2. Lau KK, Suzuki H, Novak J, Wyatt R (2010): Patogenesis of Henoch-Schönlein purpura nephritis. Pediatr Nephrol 25: 19-26.

3. Piette W, Stone M (1989): A cutaneous sign of IgA-associated small dermal vessel leukocytoclastic vasculitis in adults (Henoch- Schönlein purpura). Arch Dermatol 125: 53-56.

4. Rostoker G (2001): Schönlein-Henoch purpura in children and adults. BioDrugs 15: 99-138.

5. Kiryluk K, Moldoveanu Z, Sanders JT, et al. (2011): Aberrant glycosylation of $\operatorname{IgA} 1$ is inherited in both pediatric $\operatorname{IgA}$ nephropathy and Henoch-Schönlein purpura nephritis. Kidney Int 80: 79-87.

6. Lau KK, Suzuki H, Novak J, Wyatt RJ (2010): Pathogenesis of Henoch-Schönlein purpura nephritis. Pediatr Nephrol 25: 19-26.

7. Working Group of the International IgA Nephropathy Network and the Renal Pathology Society. Cattran DC, Coppo R, Cook HT, et al. (2009): The Oxford classification of IgA nephropathy: rationale, clinicopathological correlations, and classification. Kidney Int 76: 534-545.

8. Trimarchi H, Barratt J, Cattran DC, et al. (2017): IgAN Classification Working Group of the International IgA Nephropathy Network and the Renal Pathology Society. Conference Participants. Oxford Classification of IgA nephropathy 2016: an update from the IgA Nephropathy Classification Working Group. Kidney Int 91: 1014-1021.

9. Nasri H (2014): Oxford classification of IgA nephropathy is applicable to predict long-term outcomes of Henoch-Schönlein purpura nephritis. Iran J Allergy Asthma Immunol 13: 456-458.
10. Zhu X, Li H, Liu Y, et al. (2017): Tubular atrophy/interstitial fibrosis scores of Oxford classification combinded with proteinuria level at biopsy provides earlier risk prediction in IgA neprhopathy. Sci Rep 7: 1100.

11. Stutz F, Müller GA (2006): Renal fibrosis and the origin of the renal fibroblast. Nephrol Dial Transplant 21: 3368-3370.

12. Kimura M, Asano M, Abe K, et al. (2005): Role atrophic changes in proximal tubular cells in the peritubular deposition of type IV collagen in a rat renal ablation model. Nephrol Dial Transplant 20: 1559-1565.

13. Ruiz-Torres MP, Lopez-Ongil S, Griera M, et al. The accumulation of extracellular matrix in the kidney: conseqences on cellular function. J Nephrol 18: 334-340.

14. Minz R, Bakshi A, Chhabra S, et al. (2010): Role of myofibroblasts and collagen type IV in patients of IgA nephropathy as markers of renal dysfunction. Indian J Nephrol 20: 34-39.

15. Shuiai Z, Huijun S, Weizhong G, et al. (2017): Evaluation of TGF- $\beta 1$ and MCP- 1 expression and tubulointerstitial fibrosis in children with Henoch-Schönlein purpura nephritis and IgA nephropathy: A clinical correlation. Clinics 72: 95-102.

16. Hay ED, Zuk A (1995): Transformations between epithelium and mesenchyme: normal, pathological, and experimentally induced. Am J Kidney Dis 26: 678-690.

17. Zeisberg M, Bonner G, Maeshima Y, et al. (2001): Collagen composition and assembly regulates epitelial-mesenchymal transdifferentiation. Am J Pathol 159: 1313-1321.

18. Müler GA, Zeisberg M, Strutz F (2000): The importance tubulointerstitial damage in progressive renal disease. Nephrol Dial Transplant 15: 76-77.

19. Schwartz GJ, Muńoz A, Schneider MF, et al. (2009): New equations to estimate GFR in children with CKD. J Am Soc Nephrol 20: 629-637.

20. Mizerska-Wasiak M, Roszkowska-Blaim M (2008): Assessment of urinary collagen type IV excretion in children with IgA nephropathy. Adv Clin Exp Med 7: 129-135.

21. Kiliś-Pstrusińska K, Wikiera-Magot I, Zwolińska D, et al. (2002): Analysis of collagen IV and fibronectin in blond and urine in evaluation of nephrotic fibrosis in children with chronic glomerulonephritis. Med Sci Monit 8: 713-719.

22. Kim CH, Lim BJ, Bae YS, et al. (2014): Using the Oxford classification of IgA nephropathy to predict long-term outcomes of Henoch-Schönlein purpura nephritis in adults. Mod Pathol 27: 972-982. 